\title{
Why scientific information does not necessarily impact the decisions by human society
}

Thiago Gonçalves-Souza ${ }^{1 *}$, José Alexandre F. Diniz-Filho² and Ulysses Paulino Albuquerque ${ }^{3}$

\begin{abstract}
1 Laboratório de Síntese Ecológica e Conservação da Biodiversidade (ECOFUN), Departamento de Biologia, Universidade Federal Rural de Pernambuco, Recife, Pernambuco, Brazil.

2 Laboratório de Ecologia Teórica e Síntese, Departamento de Ecologia, Universidade Federal de Goiás, Goiânia, Goiás, Brazil.

3 Laboratório de Ecologia e Evolução de Sistemas Socioecológicos (LEA), Departamento de Botânica, Universidade Federal de Pernambuco, Recife, Pernambuco, Brazil.
\end{abstract}

* Corresponding author. $\bowtie \mathrm{E}$-mail address: tgoncalves.souza@gmail.com

\section{INTRODUCTION}

"...The investigation of bat coronaviruses becomes an urgent issue for the detection of early warning signs, which in turn minimizes the impact of such future outbreaks in China. (...) However, we should not underestimate the possibility of recombination among different bat CoVs that lead to the generation of potential pandemic viruses". This is an excerpt from the paper by Yi Fan and co-authors published in March 2019 in the journal "Viruses". Likewise, in April 2015 the co-founder of Microsoft, Bill Gates, presented a TED Talk" entitled "The new outbreak: we're not ready". In this video, Gates suggested that to get ready for the next epidemics, the society should learn with previous outbreaks (e.g., ebola) and increase investment in the global health system, just like countries do prepare for a war. However, why both recommendations from scientists, influent personalities, or a viral video ( $>26$ million views) did not prepare us for the Covid-19 pandemics? In a related matter, why does scientific information not necessarily impact the decisions of human society to act against forecasted environmental hazards?

\section{Would humans be the root of environmental problems?}

When it comes to environmental problems, we cannot ignore that human actions are practically at the root of all of them. Current literature shows evidence that our species can maintain affective relationships and have a deep psychological affinity with nature (as E. O. Wilson proposed in his "The Biophilia hypothesis", 1984) (Albuquerque et al. 2020). However, what would justify our inability to protect what we are with do we tune? There are cognitive biases that make us focus on the present, leading to less concern for the future (temporal discounting). The evolutionary roots of this behavior would lie in the fact that life expectancy in the first hominids would be extremely short, leading them to strategies focused on the present and their most urgent needs (Penn 2003, 
Henry et al. 2017). A catastrophic scenario tends to emerge when associating these cognitive biases with our current consumption patterns. How to count these biases and behavioral patterns to avoid situations with which we are currently living, depends much more than expanding our scientific knowledge base.. Kareiva and Carranza (2018) argue that the challenge lies in the commitment to design systems (ecological, regulatory, and financial) that increase our resilience. Did COVID-19 teach us this lesson?

\section{Covid-19 alerts}

Although COVID-19 has revived debates about zoonotic diseases and environmental degradation, many other infectious diseases (eg Ebola, HVI-1, and 2) originate in forest devastation, hunting and meat consumption of wild animals (see Wolfe et al. 2005, Jones et al. 2013). A strong correlation has already been found between the emergence of zoonoses and the diversity present in the world's tropical forests, especially mammals (Allen et al. 2017). It is also in these biodiversity regions where we find great biocultural diversity and a significant portion of humanity that depends on hunting wild animals (Jenkis et al. 2008, Golden et al. 2911, Carvalho et al. 2015, Ndlovu et al 2015, Riple et al 2016, Chaves et al. 2020). If the cause closest to the origin of SARSCoV-2 came from the habit of hunting wild animals, such as bats and pangolins (see Andersen et al. 2020), we have a global challenge ahead. On the one hand, human populations whose diet is based on the consumption of these animals, and on the other, a network of animal consumption to maintain the market for exotic products of medical and food curiosities (Volpato et al 2020). About exotic cuisines, Volpato et al (2020) were precise:

(...), phenomena such as COVID-19 need to be framed within discourses that redefine the perceived boundaries between human and non-human, between what are considered cultural and natural realms. From this perspective, in the economy of wild foods, often presented as prestige dishes within global imaginaries of gastronomic exclusivity, the "wild" is loosing its significance, as the wild is not wild anymore. On the other hand, the same imaginary is undermining not only local economies, but also global health. Thus, the rhetoric of the wild is increasingly reducing spaces for wildlife as much as the livelihood of those who base their economy therein. In this sense, now, maybe more than ever, that wilderness yields the paradoxical result of making the already fuzzy boundary between domesticated and wild even more fragile.

\section{How do climate change and biodiversity loss models have predicted disease outbreaks?}

Although Earth's climate naturally cycles through time, there is an ongoing climate warming and increasing of extreme weather events affected by anthropogenic activities (e.g., urbanization, forest clearing, fires) in a couple of centuries. Global forest cover has dropped $46 \%$ since the start of human civilization, with estimates of 15 billion trees cut per year (Crowther et al. 2015). Likewise, the average global temperature increased by $0.87{ }^{\circ} \mathrm{C}$ from 1850 to 2015 , a value that might still augment to $1.5^{\circ} \mathrm{C}$ until 2040 (IPCC 2019). Both climate changing and habitat loss (e.g., forest clearing) have

2 See at https://www.youtube.com/watch?v=6Af6b_wyiwl 
accelerated biodiversity loss and impacted human well-being in unprecedented ways. Indeed, there is compelling evidence that one of the adverse outcomes of climate and habitat loss is an increase in vector-borne disease outbreaks (Wu et al. 2016). The environmental journalist Katarina Zimmer wrote a "pre-pandemic" article in "National Geographic"2, where she compiled a list of examples from some leading disease ecologists and concluded: "...scientists fear that the next deadly pandemic could emerge from what lives within them".

The most typical (and worrying) scientific evidence demonstrating a link between habitat loss and disease outbreaks come from the spillover of zoonotic diseases such as HIV and Ebola. For instance, a study with 11 sites in West Africa found that hotspots of Ebolavirus spillover from bats3 to humans were also the most disturbed areas (Rulli et al. 2017). Another study demonstrated that increasing deforestation by $10 \%$ led to a $3.3 \%$ increase in Malaria along 13 years in the Brazilian Amazon. Likewise, a globalscale research shown that the accelerating forest loss in tropical regions favors an elevated risk of emerging infectious diseases (Allen et al. 2017). Land-use intensity increases the contact rates of humans with animal reservoirs which, in turn, increase the probability of a spillover of bacteria, virus, or parasites.

Scientists have also shown that warmer and rainy climates also favor vector-borne diseases (e.g., Mclntyre et al. 2017). Thus, the risk of human exposure might increase in scenarios of changing climate, as both models and empirical studies have demonstrated that temperature warming and flooding increased disease outbreaks at both local and global scales.

Climate change, biodiversity, and ecosystem health loss represent gradual changes affecting human perception.
Therefore, they are environmental hazards normalized by human societies, preventing them from taking corrective measures (Moore et al. 2019). The Environmental Scientist Frances Moore uses the boiling frog metaphor, in which a frog can die if put in water that boils slowly, but the frog can alive (although injured) if suddenly set in an already boiled water. Likewise, human societies respond quickly to extreme weather events or environmental hazards, such as the covid19 outbreak we are living now, but do not anticipate and see the big picture, in particular, the idea that all these problems are likely to be correlated.. At least in part, some ongoing debates (e.g., the discussion between the economic and environmental agendas) may also explain why deforestation and climate change do not trigger societal actions, another buffer for the long term and broad-scale view of the problems.

\section{Now what? Some reflections and future directions}

In the last weeks during the social distancing, we are watching media and (most) politicians repeatedly saying: "we must use technical information (from scientists) to decide whether or not we should keep ourselves locked down". At the same time, however, most scientists recognize that human societies do not necessarily embrace the evidence of predicted environmental hazards. Indeed, humans respond promptly to immediate environmental hazards signals (e.g., food shortage, pollution, flood, and disease outbreaks) using products and knowledge developed by scientists worldwide. This suggests that people's engagement in dealing with environmental hazards depends on urgency. However, acting after the occurrence of these environmental and 
health problems may coast more lives (and money) than anticipating them.

We argue it is time for a reflection from different parts of society. We provide a brief list both as a self-reflection and recommendation:

1. Scientists: (i) train science communication to develop skills such as communicating scientific results to the general society, (ii) engage in public policies, (iii) stimulate science popularization to foster public engagement.

2. Politics: (i) create a board of specialists at different scales (federal, state, and municipal) to produce and synthesize scientific information about predicted environmental hazards, and (ii) stimulate the engagement of scientists in public policies.

3. Media and digital influencers: (i) increase the space for "specialist" journalists and scientists in journals and TV programs, reinforcing the need to check content based on scientific evidence.

4. College and school teachers opinion-makers: (i) engage in scientific projects or scientific training to develop better skills in promoting/teaching science, and (ii) stimulate/teaching the scientific method in primary/elementary education or to the general public.

5. General society: (i) demand actions from politics in funding and supporting basic and applied research, and (ii) value scientific evidence by being receptive to the recommendations that come from scientists.

\section{CONCLUSION}

We end this Editorial by asking two fundamental questions. (i) Will society change the way it deals with environmental hazards after de Covid-19 pandemics? (ii) Will scientists be ignored again and again? The answer unfortunately, is no and yes, respectively. However, we must act towards handling and communicating better the consequences of saying "no" to the scientist's warning. The boiling frog metaphor might teach us how to deal with forecasted environmental hazards. On the one hand, scientists must improve their ability and learn how to communicate their findings better. Conversely, college teachers, politics, opinion- and decision-makers, and the general public must be aware that a gradually changing climate and the accelerated loss of biodiversity will increase environmental hazards in the future. Thus, we argue that we must work together by acting proactively toward a better relationship with nature, reconciling the economic, ecological, and environmental health agendas.

\section{REFERENCES}

Albuquerque UP, Moura JB, Silva RH, Ferreira Júnior W, Silva TC (2020) Evolutionary psychology and environmental sciences. In: Schakelford, T. (ed.). The Sage Handbook of Evolutionary Psychology.

Allen T, Murray KA, Zambrana-Torrelio C, Morse SS, Rondinini C, Di Marco M, Breit N, Olival KJ, Daszak P (2017) Global hotspots and correlates of emerging zoonotic diseases. Nature Communications 8:1124.

Andersen KG, Rambaut A, Lipkin I, Holmes EC, Garry RF (2020) The proximal origin of SARSCoV-2. Nature Medicine 26: 2-4.

Carvalho M, Rego F, Palmeirim JM, Fa JE (2015) Wild meat consumption on São Tomé Island, West Africa: Implications for conservation and local livelihoods. Ecology and Society, 2015: 20(3).

Chaves L, Alves R, Albuquerque U. Hunters' preferences and perceptions as hunting predictors in a semiarid ecosystem. Science of The Total Environment, 2020, doi: 10.1016/ j.scitotenv.2020.138494.

Fan Y, Zhao K, Shi Z-L, Zhou P (2019) Bat Coronaviruses in China. Viruses 11:210. 
Golden CD, Fernald LCH, Brashares JS, Rasolofoniaina BJR, Kremen C. Benefits of wildlife consumption to child nutrition in a biodiversity hotspot (2011). Proceedings of the National Academy of Sciences of the United States of America 108(49): 19653-6.

Henry AD, Christensen AE, Hofmann R, Steimanis I, Vollan B (2017) Influence of sea level rise on discounting, resource use and migration in small-island communities: an agent-based modelling approach. Environmental Conservation, 44 (4): 381-88.

Jenkins RKB, Racey PA (2008) Bats as bushmeat in Madagascar. Madagascar Conservation \& Development 3(1): 22-30.

Jones BA, Grace D, Kock R, Alonso S, Rushton J, Said MY, et al. (2013) Zoonosis emergence linked to agricultural intensification and environmental change. Proceedings of the National Academy of Sciences of the United States of America 110(21): 8399-404.

Kareiva P, Carranza V (2018) Existential risk due to ecosystem collapse: Nature strikes back. Futures 102: 39-50. doi:10.1016/j.futures. 2018.01.001.

MacDonald AJ, Mordecai EA (2019) Amazon deforestation drives malaria transmission, and malaria burden reduces forest clearing. Proceedings of the National Academy of Sciences 116:22212-22218.

Mclntyre KM, Setzkorn C, Hepworth PJ, Morand S, Morse AP, Baylis M (2018) Systematic assessment of the climate sensitivity of important human and domestic animals pathogens in Europe. Scientific Reports 8: 6773.

Moore FC, Obradovich N, Lehner F, Baylis P (2019) Rapidly declining remarkability of temperature anomalies may obscure public perception of climate change. Proceedings of the National Academy of Sciences 116:49054910.
Ndlovu S (2015) Names as Indigenous Knowledge for Making Meat Edible and/or Inedible: Implications on Food Security in Zimbabwe. Name and Naming: Conventional / Unconventional in Onomastics :751-62.

Penn DJ (2003) The evolutionary roots of our environmental problems: Toward a Darwinian ecology. The Quarterly Review of Biology 78(3): 275-01.

Quammen D (2012) Spillover: animal infections and the next human pandemic. 1st ed. W.W. Norton \& Co, New York.

Ripple WJ, Abernethy K, Betts MG, Chapron G, Dirzo R, Galetti M, et al. (2016) Bushmeat hunting and extinction risk to the world's mammals. Royal Society Open Science: 3(10).

Rulli MC, Santini M, Hayman DTS, D'Odorico P (2017) The nexus between forest fragmentation in Africa and Ebola virus disease outbreaks. Scientific Reports 7:41613.

Volpato G, Fontefrancesco MF, Gruppuso P et al. (2020) Baby pangolins on my plate: possible lessons to learn from the COVID-19 pandemic. $\mathrm{J}$ Ethnobiology Ethnomedicine 16: 19. https://doi.org/10.1186/ s13002-020-00366-4.

Wilson, E. O. (1984) Biophilia. Harvard University Press, Cambridge, MA.

Wolfe ND, Peter D, Marm KA, Burke DS (2005) Bushmeat hunting, deforestation, and prediction of zoonoses emergence. Emerging Infectious Diseases 11(12): 1822-7.

Wu X, Lu Y, Zhou S, Chen L, Xu B (2016) Impact of climate change on human infectious diseases: Empirical evidence and human adaptation. Environment International 86:14-23.

Received: 27 April 2020

Accepted: 30 April 2020

Published: 02 May 2020 